\title{
OPEN Wide-angle broadband antireflection coatings based on boomerang-like alumina nanostructures in visible region
}

\author{
${\text { MirKazem Omrani }{ }^{\bowtie} \text {, Mohammad Malekmohammad }}^{\bowtie}$ \& Hosein Zabolian
}

A novel boomerang-like alumina based antireflective coating with ultra-low reflectance has been produced for light incidence angles form 0 up to $45^{\circ}$. Boomerang-like alumina nanostructures have been fabricated on the BK7 glass substrates by dip-coating and surface modification via hot water treatment. To achieve the lowest residual reflectance, the effect of dip-coating rate and hot-water temperature in the treatment process has been investigated and optimized. To further investigate the boomerang-like alumina nanostructure and extract its graded refractive index profile by fitting the measured reflectance spectrum with the simulated one, a simulation based on the finite-difference time-domain (FDTD) method has been performed. The average reflectance measured at normal incidence for double-sided coated BK7 glass substrates is only $0.3 \%$ in the visible spectral region. Considering both sides, the average reflectance of the substrate decreased in the spectral range of $400-700 \mathrm{~nm}$ down to $0.4 \%$ at incidence angles of $45^{\circ}$ by applying the boomerang-like alumina antireflection coatings. The optimized single layer boomerang-like alumina coating on the curved aspheric lens exhibited a low average reflectance of less than $0.14 \%$ and an average transmittance of above $99.3 \%$ at normal incidence. The presented process is a simple and cost-effective route towards broadband and omnidirectional antireflection coatings, which have promising potential to be applied on substrates having large scales with complex geometric shapes.

The reflections of light that occurs at the interface between air and materials, due to the sharp change of refractive indices, must be eliminated in advanced optical systems to increase performance and reduce ghost images and flare. As a result, a single-layer anti-reflective coating must have a refractive index equal to the square root value of the substrate refractive index $\left(n_{\text {coat }}=\sqrt{n_{\text {sub }}}\right)$ to achieve zero reflection, where the optical thickness of the anti-reflective layer is a quarter of the wavelength $\left(n_{\text {coat }} \times \mathrm{d}=\frac{\lambda}{4} \text {, where } \mathrm{d} \text { is the physical thickness }\right)^{1,2}$. For instance, an anti-reflective coating with a refractive index of less than 1.25 is required for fused silica substrates. Since there is no known material with this refractive index, only sub-wavelength nanoporous nanostructures, which are solid materials having air pores, can fulfill this requirement. However, in the case of meeting the above conditions, a zero reflectance is achieved solely at a specified wavelength due to the uniformity of the effective refractive index along the coating thickness. To achieve a broadband anti-reflective coating, the key issue is to avoid sharp changes in the effective refractive index between the air and the substrate. The refractive index of the coating should gradually increase from the coating surface to the interface. For this purpose, multilayer coatings have been developed in which the optical thickness of each layer is at least one-quarter of the wavelength and the refractive index of the layers from top to bottom should be incremental. According to optical theory, the refractive index of a multilayer stack must satisfy the equation: $\frac{n_{1}}{n_{s}}=\frac{n_{2}}{n_{1}}=\cdots=\frac{n_{a}}{n_{k}}$, where $n_{s}$ and $n_{a}$ are the reflective indices of the substrate and of air, respectively ${ }^{3}$.

On the other hand, modern optical systems are often based on lenses with different radii of curvature, and the incoming light impinges on the lens surface under various incidence angles. Therefore, providing an omnidirectional anti-reflective coating is of considerable importance. So far, the multifunctional broadband antireflective coatings are commonly prepared by physical vapor deposition (PVD) and chemical vapor deposition (CVD) techniques such as plasma-enhanced CVD, sputtering and evaporation ${ }^{4-6}$. However, thickness gradients can occur on curved substrate surfaces due to shadowing effects. Due to changes in film thickness, the coating in steep inclinations of the substrate surface does not meet the desired specification and leads to increased 

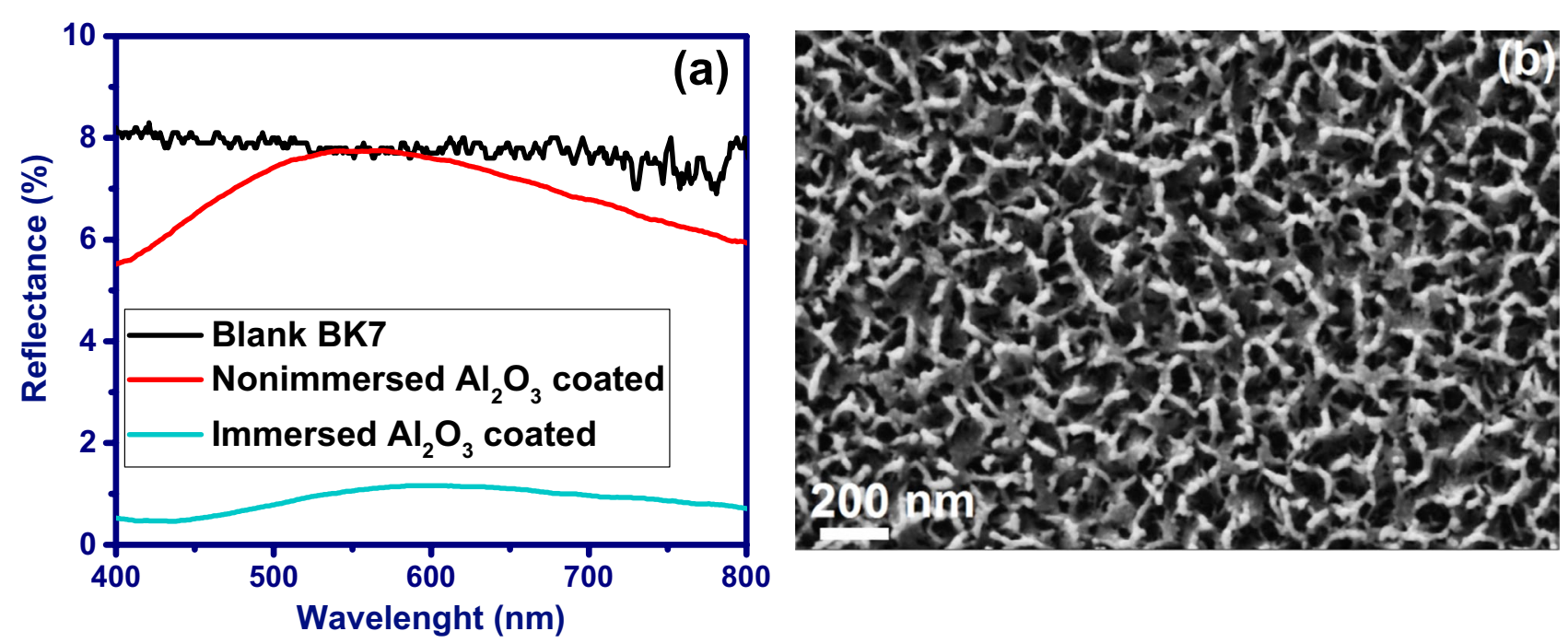

Figure 1. (a) Reflectance spectra measured from blank $\mathrm{BK} 7$ and double-side $\mathrm{Al}_{2} \mathrm{O}_{3}$ coated $\mathrm{BK} 7$ substrates with and without hot-water treatment. (b) Field emission scanning electron micrograph of the surface of $\mathrm{Al}_{2} \mathrm{O}_{3}$ thin film with boomerang-like structure.

reflection ${ }^{7}$. Several methods have been proposed to solve this dilemma, in particular the use of shadowing masks and substrate-rotational systems ${ }^{8-10}$. However, these methods capabilities are limited to constrained geometric shapes, such as cylinders or convex lenses.

In recent years, sub-wavelength coatings with gradient refractive index profiles have been extensively studied in the hope of providing omnidirectional and broadband anti-reflective properties ${ }^{1,11-15}$. Moth's eye nanostructures that provide gradual refractive index changes from the structure's surface to the interface minimize reflections well over a wide range of wavelengths and incident angles ${ }^{16-23}$. However, such nanostructures are usually prepared by photolithographic techniques, which are difficult to produce in large areas and on curved surfaces. Compared to these methods, the sol-gel method not only can be used in large substrates with complex shapes, but also has a controllable desirable microstructure to achieve low refractive index and hydrophobic performance, as well as low-cost simple operation process ${ }^{24}$.

To maximize light transmission, the coating nanostructure must be smaller than the wavelength of light to minimize scattering losses. Yamaguchi et al. have developed alumina-based flower-like structures with a roughness of less than $100 \mathrm{~nm}$ using the sol-gel method, which has a gradient density ${ }^{25,26}$. The average refractive index of the nanostructure in the specified depth gradually changes from the coating's surface to the interface, like a moth's eye structures. To create a gradient density in the alumina nano-porous structure, the coatings have been treated with hot water. They achieved a reflectance of less than $0.5 \%$ (1-side) in the visible spectral region by coating the soda-lime silica glass with flower-like alumina nanostructures using the dip-coating $\operatorname{method}^{27}$. However, as of yet, no study has been provided on the effect of dipping-withdrawing rate and hot water treatment temperature; the case which play a determinative role in the thickness and inclination of the effective refractive index changes on the optical response of sol-gel prepared alumina nanostructures.

Here, inspired by the manufacturing method of anti-reflective coatings based on flower-like alumina, in a sol-gel process, the boomerang-like alumina nanostructure has been coated on the BK7 glass substrate. The influence of hot-water treatment temperature and dipping-withdrawing rate has been investigated in order to achieve a high performance anti-reflective coating with high transparency. The omnidirectional property of the proposed coating due to having an inclined refractive index profile has been investigated and the optimized coating has been applied on curved aspheric lenses.

\section{Results and discussion}

Figure 1a shows the reflectance spectra of the blank BK7 substrate compared to the double-side porous alumina coated BK7 (dipping-withdrawing rate of $3 \mathrm{~mm} / \mathrm{s}$ ) in both the presence and absence of the hot-water treatment process. The low refractive index of porous alumina $(\sim 1.4)$ compared to BK7 substrate $(\sim 1.51)$ led to a decrease in light reflectance; the reduction which was significantly increased while the coated substrate was immersed in hot water. Hot-water treatment leads to the formation of boomerang-like structures with a roughness of less than $50 \mathrm{~nm}$ during the dissolution of porous $\mathrm{Al}_{2} \mathrm{O}_{3}$ film on its smooth and flat surface (Fig. 1b). This in turn leads to an increase in the density of alumina with an increasing distance from the coating's surface, creating a gradient refractive index profile, the same as a moth's eye nanostructure. However, the boomerang-like structure may not be perfectly formed along the coating thickness and there may be a gap of porous alumina between the boomerang-like structure and the substrate. Therefore, optimization of dipping-withdrawing rate and hot-water treatment temperature, which has a direct impact on the thickness and inclination of the refractive index profile, is important to achieve high anti-reflective properties.

Figure 2 shows the hot-water treatment temperature effect on the optical response of double-side boomerang-like alumina coated BK7 substrates with different dipping-withdrawing rates $(1,2$ and $3 \mathrm{~mm} / \mathrm{s})$. Previous 

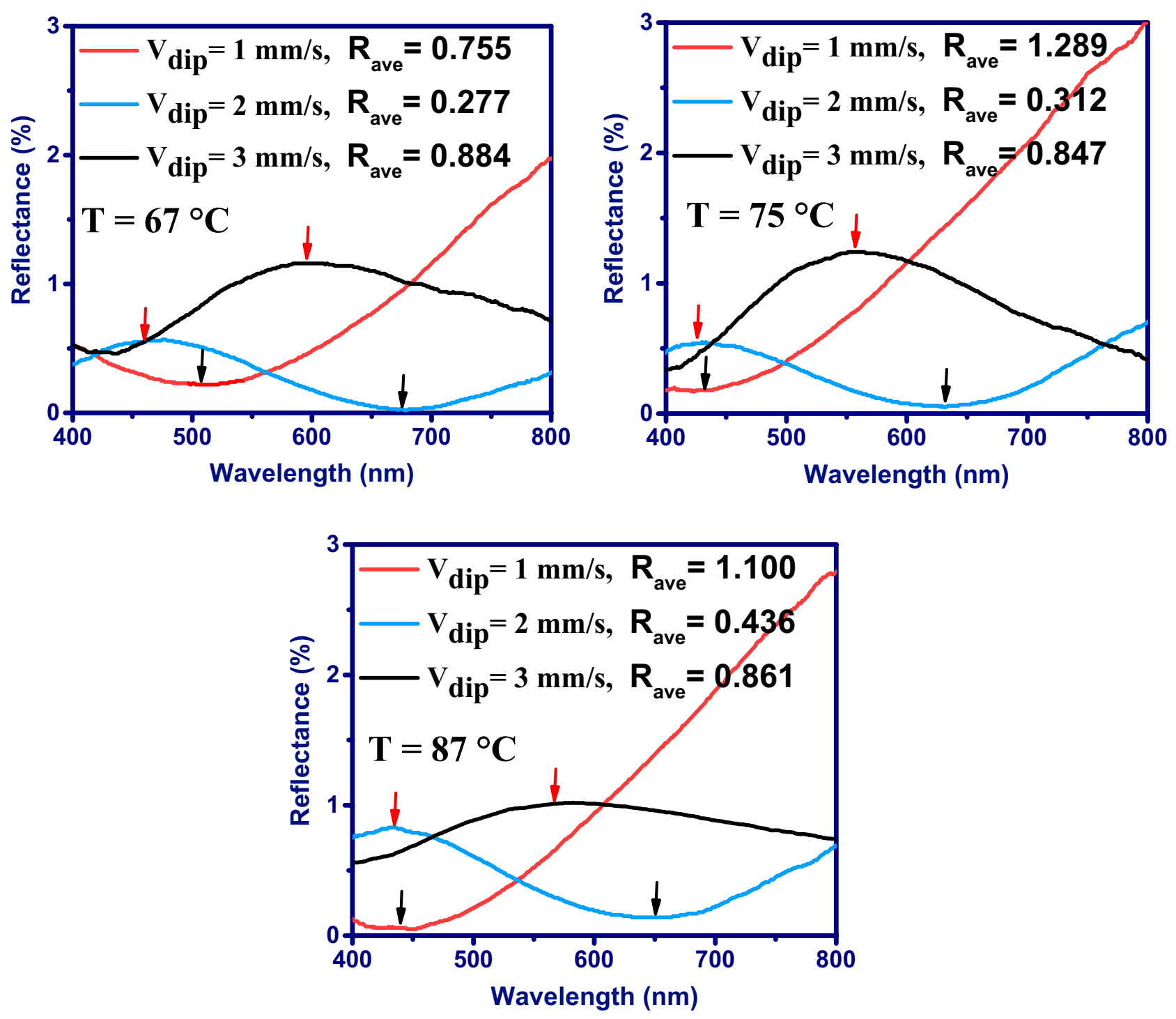

Figure 2. Reflectance spectra measured from double side coated BK7 substrates with boomerang-like $\mathrm{Al}_{2} \mathrm{O}_{3}$ films at different dipping-withdrawing rates $\left(\mathrm{V}_{\text {dip }}\right)$ and hot-water treatment temperatures $(\mathrm{T})$.

studies have shown that high porosity occurs in the alumina layer at treatment temperatures above $60^{\circ} \mathrm{C}^{25,26,28}$. Therefore, for temperatures above 60 degrees, the effect of treatment temperature on the optical performance of alumina coating has been investigated. At all hot-water treatment temperatures of $67^{\circ} \mathrm{C}, 75^{\circ} \mathrm{C}$ and $87^{\circ} \mathrm{C}$, with increasing dipping-withdrawing rate from 1 to $2 \mathrm{~mm} / \mathrm{s}$, initially the reflectance decreases, then with increasing the rate up to $3 \mathrm{~mm} / \mathrm{s}$, the reflectance begin to increase. Among all these samples, the coatings prepared with a dipping-withdrawing rate of $2 \mathrm{~mm} / \mathrm{s}$ (creates a thickness of about $200 \mathrm{~nm}^{29}$ ) shows the lowest light reflectance with average reflectance $\left(\mathrm{R}_{\text {ave }}\right)$ of $0.277,0.312$ and $0.436 \%$ for hot-water treatment temperatures of $67^{\circ} \mathrm{C}, 75^{\circ} \mathrm{C}$ and $87^{\circ} \mathrm{C}$, respectively. Since the thickness of the coated layer is directly related to the dipping-withdrawing rate, increasing the rate causes the reflectance spectrum to have red-shifts as the layer thickness increases (as shown in Fig. 2). The blue-shift of the reflectance spectrum with increasing hot-water treatment temperature from $67^{\circ} \mathrm{C}$ to $75^{\circ} \mathrm{C}$ and $87^{\circ} \mathrm{C}$ can be due to more dissolution of alumina and reduction of layer thickness. Excessive increase of this dissolution in the upper levels of alumina boomerang-like structure, which is more exposed to hot water, can lead to increased light reflectance by increasing the slope of the refractive index profile. For example, in the coating prepared with the rate of $2 \mathrm{~mm} / \mathrm{s}$, the light reflectance has increased over the entire visible spectral region due to increasing the treatment temperature from $75^{\circ} \mathrm{C}$ to $87^{\circ} \mathrm{C}$, while the layer thickness has not significantly changed (inferred from this observation that there was no shift in the reflectance spectrum). Therefore, increasing light reflectance can be attributed to increasing the slope of the refractive index profile during high dissolution of the upper levels of the boomerang-like structure of alumina.

To further investigate the boomerang-like alumina nanostructure and extract its refractive index profile by fitting the measured reflectance spectrum with the simulated one, a simulation based on the finite-difference timedomain (FDTD) method has been performed (Fig. 3). The boomerang-like unit structure, inspired by the FESEM image of the sample surface (Fig. 3a), has been used to design the alumina nanostructure. Nano-boomerangs 


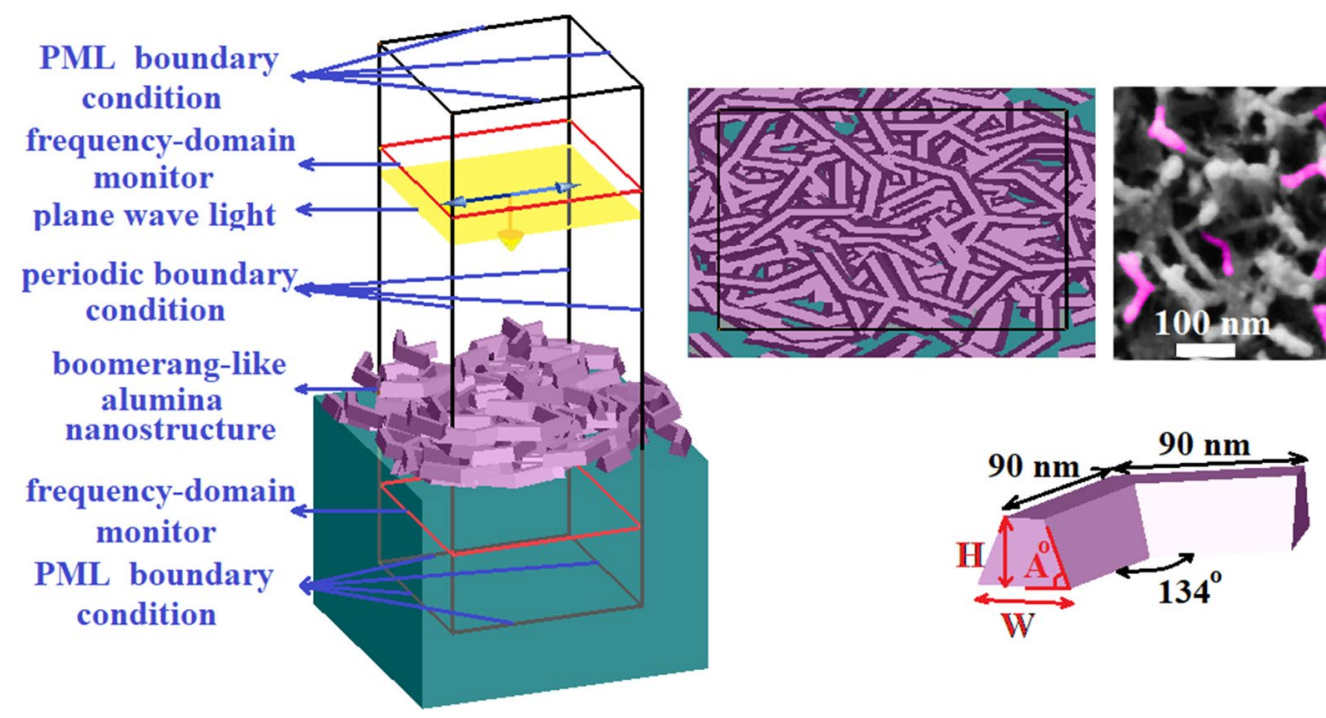

(a)
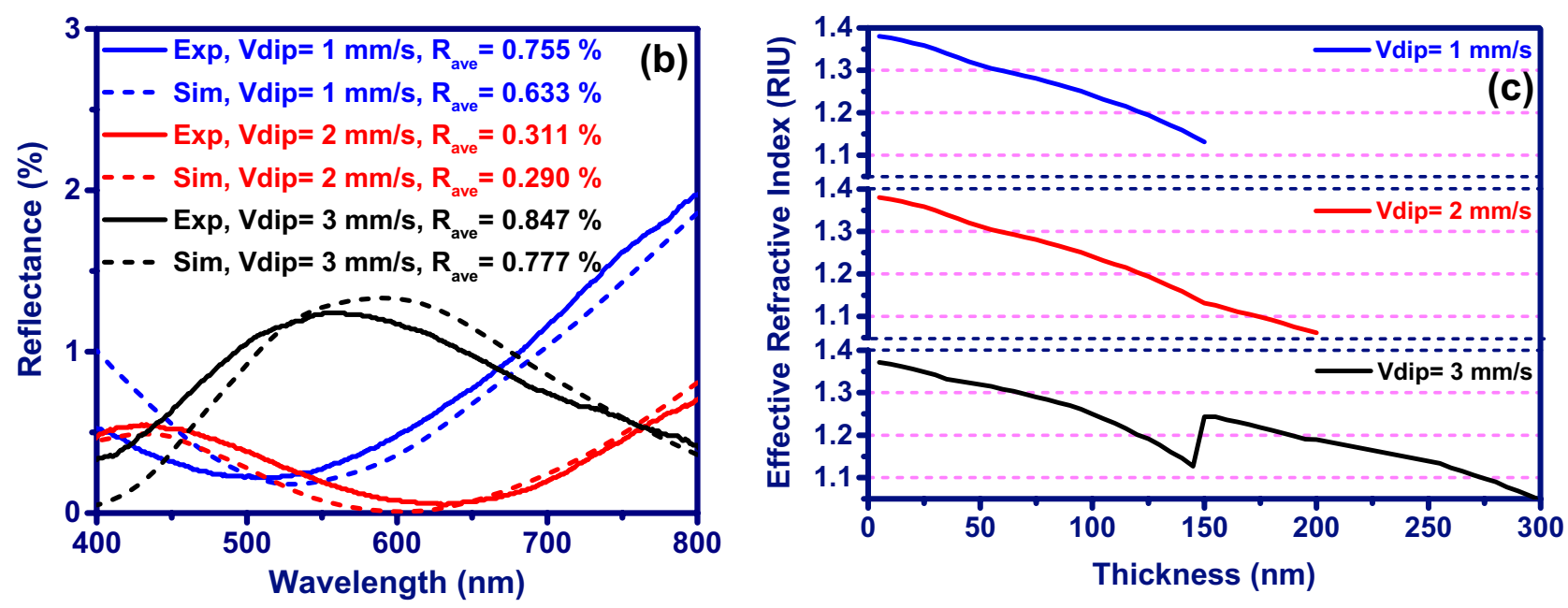

Figure 3. (a) Schematic diagram of the simulation model: perspective view (left) and top view (right). (b) Spectral reflectance of double side coated samples with different dipping-withdrawing rates $\left(\mathrm{V}_{\text {dip }}\right)$ from Fig. 2 (solid line) and simulated spectral reflectance (dash line). (c) The relationships between thickness position and effective refractive index of boomerang-like $\mathrm{Al}_{2} \mathrm{O}_{3}$ films produced at different dipping-withdrawing rates $\left(\mathrm{V}_{\text {dip }}\right)$.

with a height, $\mathrm{H}$ of $50 \mathrm{~nm}$, a width, $\mathrm{W}$ of 30 and $40 \mathrm{~nm}$, and a basic angle, A of 77-83 degrees have been randomly distributed (random position and rotation) on the surface of BK7 substrate so that thicknesses of 150, 200 and $300 \mathrm{~nm}$ with gradient refractive index profiles (Fig. 3c) have been created for the coatings fabricated at dipping-withdrawing rates of 1,2 and $3 \mathrm{~mm} / \mathrm{s}$, respectively. Figure $3 \mathrm{~b}$ shows the measured reflectance spectra of the fabricated anti-reflective coatings compared to the simulation results. The calculated reflectance spectrum is in good agreement with the experimental spectra, which shows that the modeling performed in this work can well describe the optical performance of the device. Figure $3 c$ shows the variation of effective refractive index with thickness for coated alumina nanostructures at rates of 1,2 and $3 \mathrm{~mm} / \mathrm{s}$. Among them, the boomerang-like alumina nanostructure coated at a rate of $2 \mathrm{~mm} / \mathrm{s}$ and treated with deionized hot water for $30 \mathrm{~min}$, which provides a gradient refractive index profile rated from 1.05 to 1.4 along the $200 \mathrm{~nm}$ thickness, has been presented the best optical performance with the least amount of reflectance (Fig. 3b). The effective refractive index along the alumina nanostructure has been calculated using Eq. (1) provided by Yoldas for porous nanostructures ${ }^{30}$.

$$
n_{p}^{2}=\left(n^{2}-1\right)\left(1-\frac{p}{100}\right)+1,
$$

where $p, n$, and $n_{p}$ are the percent porosity, index of nonporous material, and index of porous material, respectively. The percent porosity has been calculated using an index monitor along the nanostructure thickness and image processing.

Figure 4a shows the reflectance and transmittance spectra of double-side boomerang-like alumina coated BK7 substrates with the dipping-withdrawing rate of $2 \mathrm{~mm} / \mathrm{s}$ and the hot-water treatment temperature of $67^{\circ} \mathrm{C}$ at the incidence angles of $0^{\circ}, 12^{\circ}, 30^{\circ}$ and $45^{\circ}$. At the case of normal incidence, the average reflectance of BK7 has reduced from about $8 \%$ to $0.3 \%$ in the visible spectral region. Measurements at all incidence angles show 

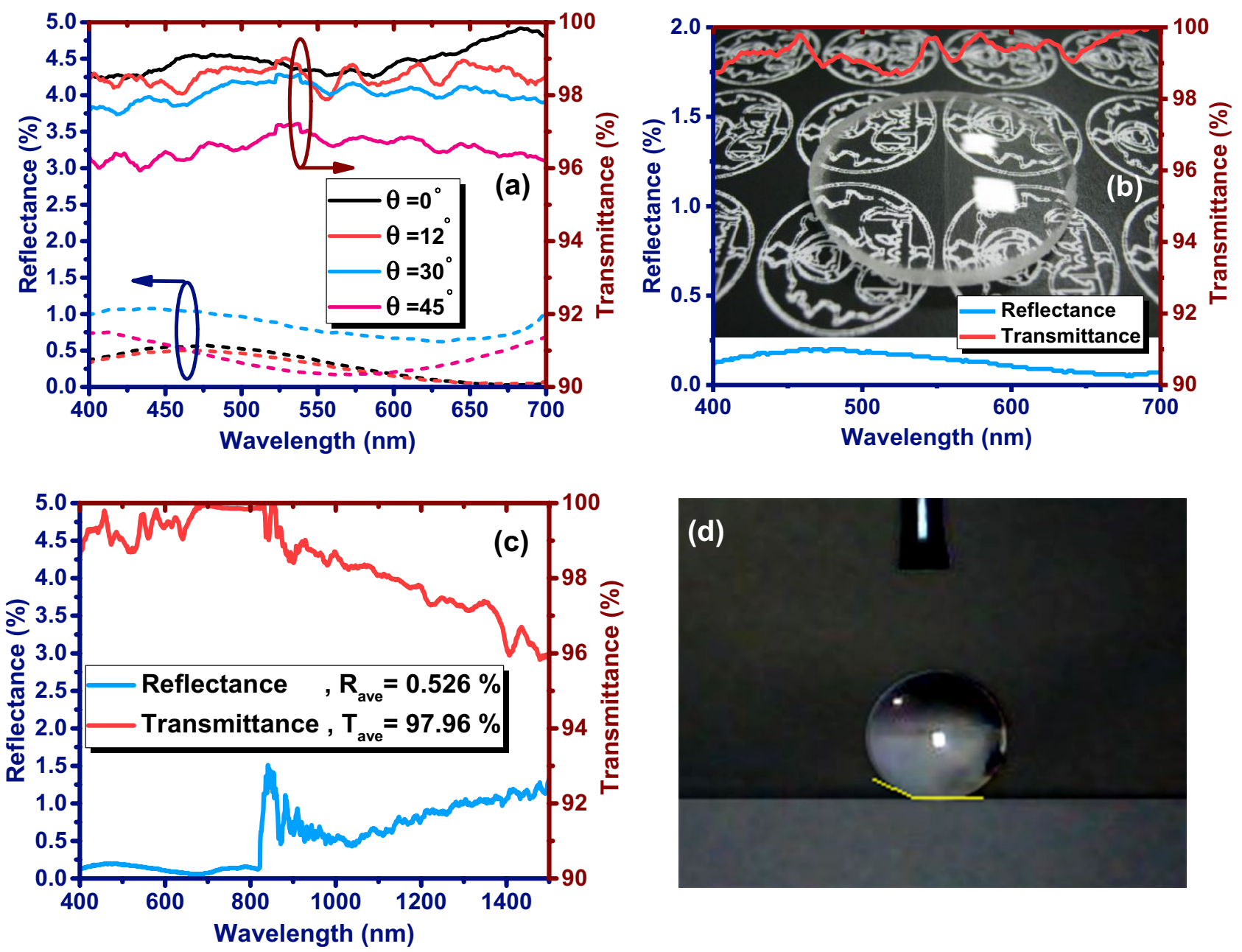

Figure 4. (a) Reflectance and transmittance spectra measured from double side coated BK7 substrates with boomerang-like $\mathrm{Al}_{2} \mathrm{O}_{3}$ films at incident angles of $0^{\circ}, 12^{\circ}, 30^{\circ}$ and $45^{\circ}$. (b) Reflectance and transmittance across a boomerang-like alumina coated lens surface measured under light at normal incidence. The background image in (b) shows that the transparency of the BK7 lens (the right part of lens) enhances remarkably in the presence of boomerang-like alumina coating (the left part of lens). (c) Reflectance and transmittance across a boomeranglike alumina coated lens surface measured under light at normal incidence. (d) Photograph of water droplet on the superhydrophobic surfaces of boomerang-like alumina coated BK7 substrate.

a low average reflectance of less than $0.9 \%$. Similarly, the average transmittance at the incidence angle of $45^{\circ}$ is above $96.5 \%$, which is significantly higher than $92 \%$ for the blank BK7 at the normal incidence. Subsequently, the optimized boomerang-like alumina coating is applied to a curved aspheric BK7 lens and its anti-reflective performance is investigated (Fig. 4b). The measurements showed an average reflectance of less than $0.14 \%$ and an average transmittance of above $99.3 \%$ in the visible spectral region (400-700 nm). To realize the effect of broadband anti-reflection property in the visible wavelength range, optical images for a lens with and without the proposed coating that was exposed to white light are shown in the background of Fig. $4 \mathrm{~b}$. The right part of the lens (without the coating) looks a bit white and misty gray, and the image behind the lens cannot be clearly seen due to the ghost image from the light. In general, the uncoated part reflects all kinds of visible light, and the lens appears white. On the contrary, the left part of the lens (with the coating) shows increased transparency, and the real color of the background image is reproduced phenomenally even at oblique incidence angles.

It is noteworthy that this anti-reflective property of the proposed coating is not only restricted to the visible spectral region but also provide low reflectance (average of $0.526 \%$ ) with very high transparency (average transmittance of $97.96 \%$ ) in the wavelength range of $400-1500 \mathrm{~nm}$ (Fig. 4c). Above all, this nanostructure shows hydrophilic properties due to its roughness of less than $50 \mathrm{~nm}$, which provides superhydrophobic properties during the reduction of surface free energy using fluorosilane (Fig. $4 \mathrm{~d}$ ). In the case of BK7 glass substrate coated with boomerang-like $\mathrm{Al}_{2} \mathrm{O}_{3}$ thin film, the contact angle for water drop is about $155^{\circ}$. Here, heptadecafluorodecyltrimethoxysilane, which is one of the fluoroalkyltrimethoxysilanes (FASs) was spin coated over boomerang-like alumina coatings at $3000 \mathrm{RPM}$ for $60 \mathrm{~s}$ and annealed at $180^{\circ} \mathrm{C}$ for $30 \mathrm{~min}$ to obtain low energy surfaces.

The various techniques used to fabricate alumina-based single-layer anti-reflective coatings have been summarized in Table 1. Lertvanithphol et al. have fabricated $\mathrm{Al}_{2} \mathrm{O}_{3}$ nanoflake films on a glass slide by reactive magnetron sputtering and surface modification via hot water treatment and alkali treatment ${ }^{31}$. The developed anti-reflective 


\begin{tabular}{|l|l|l|l|l|}
\hline Substrate & Fabrication method & $\mathbf{A l}_{2} \mathbf{O}_{3}$ nanostructure & Coated (uncoated) average $\mathbf{R}(\%)$ & Ref \\
\hline Glass & Reactive magnetron sputtering & Nanoflake & $4.12(9.19)$ & 31 \\
\hline Soda lime glass & Spin-coating & Nanoflakes & $3.04(7.29)$ & 32 \\
\hline Solar cover glass & Wire bar coating & Nanoflakelet & $1.59(11.61)$ & 33 \\
\hline PMMA & Dip-coating & Pseudo-boehmite nanocrystals & $1.44(8.06)$ & 26 \\
\hline Soda lime glass & Dip-coating & Flowerlike & $1.16(9.76)$ & 25 \\
\hline Soda lime glass & Atomic layer deposition & Grasslike & $0.77(8.09)$ & 28 \\
\hline BK7 glass & Dip-coating & Boomeranglike & $0.31(7.85)$ & T.W \\
\hline
\end{tabular}

Table 1. Comparison of various fabrication techniques used for $\mathrm{Al}_{2} \mathrm{O}_{3}$ based single-layer antireflection coatings in visible region $(400-700 \mathrm{~nm})$.

coating reduced the average reflectance (both sides) from $9.19 \%$ to $4.12 \%$. Using a solution-based approach and spin coating technique, Sutha et al. have developed an amorphous alumina coating with an interconnected porous network of nanoflakes on a soda glass substrate ${ }^{32}$. The $300 \mathrm{~nm}$ thick coating produced an average reflectance of 3.04\%. The hierarchical pseudo-boehmite nanoflakelets fabricated using custom-made wire bar coater on solar cover glass by Joghee et al. reduced light reflectance to $1.59 \%^{33}$. In another study, pseudo-boehmite nanocrystals formed on the surface of alumina gel by immersion in hot water, in which alumina was coated on the poly (methyl methacrylate) PMMA substrate using sol-gel process and dip-coating technique, decreased the average reflectance from $8.06 \%$ to $1.44 \%^{26}$. Using a similar manufacturing process, Yamaguchi et al. have produced flower-like alumina nanostructures on the soda glass substrate, which yielded an average reflectance of $1.16 \%$ in the visible region ${ }^{25}$. Uniquely, Kauppinen et al. have fabricated a grass-like alumina-based anti-reflective coating with a graded refractive index profile using atomic layer deposition (ALD) and the hot-water treatment process on soda glass. By investigating and optimizing the water temperature in the treatment process, they reduced the average reflectance from $8.09 \%$ to $0.77 \%{ }^{28}$. Considering all of the above studies, we have used a cost-effective and simple sol-gel process in which boomerang-like alumina nanostructures have been fabricated on the BK7 substrate in the environment atmosphere without humidity control. This anti-reflective coating, which can be easily fabricated on aspheric lens using the proposed method, has achieved an average reflectance (both sides) of less than $0.5 \%(\sim 0.31 \%)$.

\section{Conclusion}

In conclusion, an omnidirectional and broadband antireflection coating based on the boomerang-like alumina nanostructures prepared by dip-coating and hot-water treatment has been demonstrated. The effects of hot water treatment temperature and the rate of dip-coating, which determines the thickness of the anti-reflective coating, on its optical performance have been investigated. A low reflectance with an average reflectance of less than $0.3 \%$ was realized in the visible spectral region at normal incidence (double-side) for the boomerang-like alumina nanostructures fabricated with a rate of $2 \mathrm{~mm} / \mathrm{s}(\sim 200 \mathrm{~nm})$ and a hot water treatment temperature of $67^{\circ} \mathrm{C}$. The omnidirectional properties of the developed coating are discussed for incidence angles ranging from 0 to $45^{\circ}$. The average reflectance for a double-side coated BK7 substrate has been less than $0.4 \%$ at $45^{\circ}$ incidence angle. An average transmittance of above $99.3 \%$ with optical losses of $0.56 \%$ is achieved for a double-side coated curved aspheric BK7 lens. The proposed coating superiority is that the boomerang-like alumina nanostructure can be applied on inclined surfaces in a broad wavelength range because of having a gradient refractive index profile. In addition, the complete antireflection system can be coated in one process followed by one hot-water treatment.

\section{Methods}

Materials and preparation of $\mathrm{Al}_{2} \mathrm{O}_{3}$ sol. Aluminum-tri-sec-butoxide $\left(\mathrm{Al}(\mathrm{O}-\mathrm{sec}-\mathrm{Bu})_{3}\right)$ was used as a starting material. $\mathrm{Al}(\mathrm{O}-\mathrm{sec}-\mathrm{Bu})_{3}$ and isopropyl alcohol (i-PrOH) were mixed and stirred at room temperature for $20 \mathrm{~min}$. Ethylacetoacetate (EAcAc) was added to the solution as a chelating agent, and the solution was stirred for $20 \mathrm{~min}$. Then, diluted deionized water with $\mathrm{i}-\mathrm{PrOH}$ was added dropwise to the solution for hydrolysis process. The molar ratios of EAcAc, $\mathrm{H}_{2} \mathrm{O}$ and i-PrOH to $\mathrm{Al}(\mathrm{O}-\mathrm{sec}-\mathrm{Bu})_{3}$ were kept to be 1,1 and 20 , respectively 27 . All materials were obtained from Merck Chemicals.

Film preparation and characterization. The coating was deposited on BK7 glasses via dip-coating manner (with various drawing speed) in an ambient atmosphere without the humidity control. The obtained coating were heat-treated at $400{ }^{\circ} \mathrm{C}$ for $30 \mathrm{~min}$ to get porous $\mathrm{Al}_{2} \mathrm{O}_{3}$ films ${ }^{27,29}$. Then the porous $\mathrm{Al}_{2} \mathrm{O}_{3}$ coatings were immersed in hot water (with various temperature) for $60 \mathrm{~min}$ and, after being dried in an ambient atmosphere, were heat-treated again at $400{ }^{\circ} \mathrm{C}$ for $30 \mathrm{~min}$. UV-visible spectrophotometer (Shimadzu, UV-3100) was used to measure the transmittance and reflectance of the coatings. The microstructural details of the coatings were investigated using high-resolution field emission scanning electron microscopy (FESEM, model Sigma VP, Zeiss).

Received: 15 November 2021; Accepted: 3 January 2022

Published online: 18 January 2022 


\section{References}

1. Raut, H. K., Ganesh, V. A., Nair, A. S. \& Ramakrishna, S. Anti-reflective coatings: A critical, in-depth review. Energy Environ. Sci. 4, 3779-3804 (2011).

2. Macleod, H. A. Thin Film Optical Filters, ed. Bristol, UK Inst. Phys. Pub (2001).

3. Li, X., Gao, J., Xue, L. \& Han, Y. Porous polymer films with gradient-refractive-index structure for broadband and omnidirectional antireflection coatings. Adv. Funct. Mater. 20, 259-265 (2010).

4. Buskens, P., Burghoorn, M., Mourad, M. C. D. \& Vroon, Z. Antireflective coatings for glass and transparent polymers. Langmuir 32, 6781-6793 (2016).

5. Keshavarz Hedayati, M. \& Elbahri, M. Antireflective coatings: Conventional stacking layers and ultrathin plasmonic metasurfaces, a mini-review. Materials (Basel) 9, 497 (2016).

6. Chuang, S.-Y. et al. Nanoscale of biomimetic moth eye structures exhibiting inverse polarization phenomena at the Brewster angle. Nanoscale 2, 799-805 (2010).

7. Pfeiffer, K., Ghazaryan, L., Schulz, U. \& Szeghalmi, A. Wide-angle broadband antireflection coatings prepared by atomic layer deposition. ACS Appl. Mater. Interfaces 11, 21887-21894 (2019).

8. Sassolas, B. et al. Masking technique for coating thickness control on large and strongly curved aspherical optics. Appl. Opt. 48, 3760-3765 (2009).

9. Gross, M., Dligatch, S. \& Chtanov, A. Optimization of coating uniformity in an ion beam sputtering system using a modified planetary rotation method. Appl. Opt. 50, C316-C320 (2011).

10. Glocker, D., Lanzafame, J., Belan, R., Griffin, N. \& Armstrong, S. System for sputtering uniform optical coatings on flat and curved surfaces without masks (2016)

11. Kaddouri, A. M., Kouzou, A., Hafaifa, A. \& Khadir, A. Optimization of anti-reflective coatings using a graded index based on silicon oxynitride. J. Comput. Electron. 18, 971-981 (2019).

12. Wilson, C. R. et al. Anti-reflective structured surfaces on soda-lime windows for high power laser applications. in Advanced Optics for Imaging Applications: UV through LWIR V vol. $11403114030 \mathrm{H}$ (2020).

13. Liu, F. et al. High performance ZnS antireflection sub-wavelength structures with HfO 2 protective film for infrared optical windows. Opt. Express 29, 31058-31067 (2021).

14. Pickering, T., Shanks, K. \& Sundaram, S. Modelling technique and analysis of porous anti-reflective coatings for reducing wide angle reflectance of thin-film solar cells. J. Opt. 23, 25901 (2021).

15. Behera, S., Fry, P. W., Francis, H., Jin, C.-Y. \& Hopkinson, M. Broadband, wide-angle antireflection in GaAs through surface nanostructuring for solar cell applications. Sci. Rep. 10, 1-10 (2020).

16. Bernhard, C. G. Structural and functional adaptation in a visual system. Endeavour 26, 79-84 (1967).

17. Kikuta, H., Toyota, H. \& Yu, W. Optical elements with subwavelength structured surfaces. Opt. Rev. 10, 63-73 (2003).

18. Wilson, S. J. \& Hutley, M. C. The optical properties of'moth eye'antireflection surfaces. Opt. Acta Int. J. Opt. 29, 993-1009 (1982).

19. Huh, D., Choi, H.-J., Byun, M., Kim, K. \& Lee, H. Long-term analysis of PV module with large-area patterned anti-reflective film. Renew. Energy 135, 525-528 (2019).

20. Xu, H. et al. Biomimetic moth-eye anti-reflective poly-(methyl methacrylate) nanostructural coating. J. Bionic Eng. 16, 1030-1038 (2019).

21. Lim, S. H. et al. Nanopatterned polymer molds using anodized aluminum templates for anti-reflective coatings. Polymers (Basel) 13, 3333 (2021).

22. Oh, K.-S., Cho, S.-H., Choi, J.-Y., Lee, K. \& Chan, S. Improved reliability PERC PV modules with moth-eye nanostructured optical films using nano imprint lithography. Microelectron. Reliab. 114320 (2021).

23. Choi, J. S., An, J. H., Lee, J.-K., Ku, S. J. \& Kang, S. M. Analysis of optical and wetting properties of a biomimetic anti-reflective surface for practical application. J. Mech. Sci. Technol. 35, 3559-3567 (2021).

24. Zhang, S., Xiao, P., Wang, P., Luo, J. \& Jiang, B. Spherical-chain silica with super-hydrophobic surface and ultra-low refractive index for multi-functional broadband antireflective coatings. Sol. Energy 207, 1222-1230 (2020).

25. Yamaguchi, N., Tadanaga, K., Matsuda, A., Minami, T. \& Tatsumisago, M. Antireflective properties of flowerlike alumina thin films on soda-lime silica glass substrates prepared by the sol-gel method with hot water treatment. Thin Solid Films 515, 3914-3917 (2007).

26. Tadanaga, K. et al. Anti-reflective properties of nano-structured alumina thin films on poly (methyl methacrylate) substrates by the sol-gel process with hot water treatment. Thin Solid Films 516, 4526-4529 (2008).

27. Yamaguchi, N., Tadanaga, K., Matsuda, A., Minami, T. \& Tatsumisago, M. Anti-reflective coatings of flowerlike alumina on various glass substrates by the sol-gel process with the hot water treatment. J. Sol-gel Sci. Technol. 33, 117-120 (2005).

28. Kauppinen, C., Isakov, K. \& Sopanen, M. Grass-like alumina with low refractive index for scalable, broadband, omnidirectional antireflection coatings on glass using atomic layer deposition. ACS Appl. Mater. Interfaces 9, 15038-15043 (2017).

29. Tadanaga, K., Katata, N. \& Minami, T. Super-water-repellent Al2O3 coating films with high transparency. J. Am. Ceram. Soc. 80, 1040-1042 (1997)

30. Yoldas, B. E. Investigations of porous oxides as an antireflective coating for glass surfaces. Appl. Opt. 19, 1425-1429 (1980).

31. Lertvanithphol, T. et al. Facile fabrication and optical characterization of nanoflake aluminum oxide film with high broadband and omnidirectional transmittance enhancement. Opt. Mater. 111, 110567 (2021).

32. Sutha, S., Suresh, S., Raj, B. \& Ravi, K. R. Transparent alumina based superhydrophobic self-cleaning coatings for solar cell cover glass applications. Sol. Energy Mater. Sol. Cells 165, 128-137 (2017).

33. Joghee, S. H. et al. Superhydrophobic coatings based on pseudoboehmite nanoflakelets for sustainable photovoltaic energy production. ACS Appl. Nano Mater. 3, 9899-9911 (2020).

\section{Author contributions}

M. K. Omrani: Conceptualization, Validation, Formal analysis, Investigation, Writing_original draft, Writingreview \& editing, Resources, Visualization, Supervision, Project administration. M. Malekmohammad: Supervision, Writing — review \& editing. H. Zabolian: Writing—review \& editing.

\section{Competing interests}

The authors declare no competing interests.

\section{Additional information}

Correspondence and requests for materials should be addressed to M.O. or M.M.

Reprints and permissions information is available at www.nature.com/reprints.

Publisher's note Springer Nature remains neutral with regard to jurisdictional claims in published maps and institutional affiliations. 
(c) (i) Open Access This article is licensed under a Creative Commons Attribution 4.0 International cc) License, which permits use, sharing, adaptation, distribution and reproduction in any medium or format, as long as you give appropriate credit to the original author(s) and the source, provide a link to the Creative Commons licence, and indicate if changes were made. The images or other third party material in this article are included in the article's Creative Commons licence, unless indicated otherwise in a credit line to the material. If material is not included in the article's Creative Commons licence and your intended use is not permitted by statutory regulation or exceeds the permitted use, you will need to obtain permission directly from the copyright holder. To view a copy of this licence, visit http://creativecommons.org/licenses/by/4.0/.

(C) The Author(s) 2022 